\title{
Research on the Influence of Working Hours on Obesity of Urban Workers in China
}

\author{
Shulei Ding, Cuihua Liu* \\ Department of Political Economy, Business School, Beijing Normal University, Beijing, China \\ Email address: \\ dsl@bnu.edu.cn (Shulei Ding), chl@bnu.edu.cn (Cuihua Liu) \\ ${ }^{*}$ Corresponding author \\ To cite this article: \\ Shulei Ding, Cuihua Liu. Research on the Influence of Working Hours on Obesity of Urban Workers in China. American Journal of Health \\ Research. Vol. 8, No. 6, 2020, pp. 102-107. doi: 10.11648/j.ajhr.20200806.12
}

Received: October 21, 2020; Accepted: October 30, 2020; Published: November 9, 2020

\begin{abstract}
Background: China's obesity rate has grown "explosively" in the past few decades, and overtime work has become the norm for urban workers in China. It is of great significance to investigate the influence of working hours on obesity in order to prevent obesity and regulate the labor market. Methods: Based on the 2018 China Family Panel Studies, this paper first uses the logit regression method to investigate the effect of working hours on obesity of urban workers in China, and then uses the intermediary effect model to investigate the intermediary effect of weekly exercise time and sleep time. Finally, heterogeneity was analyzed for different gender and income groups. Results: (1) Urban workers who work more than 40 hours a week are more likely to be obese than those who work less than 40 hours a week. (2) The Mediator Model found that: in the conduction mechanism of working hours affecting obesity, week exercise time (less than 30 minutes per day) and sleep time (less than 8 hours per working day) both serve as a mediator, and the mediating effect of exercise time is greater than that of sleep time. That means, working more than 40 hours a week cannot only directly increase the risk of obesity among urban workers, but also indirectly increase their risk of obesity by reducing their exercise time and working-day sleep time. (3) A heterogeneity regression analysis found that, compared with urban workers who work less than 40 hours a week, working more than 40 hours a week has a greater impact on obesity among women and low-income groups. Conclusions: The above studies show that, obesity as a complex multifactorial disease, not only genetic, dietary and environmental factors should be taken into account, but also employee week work hours should be considered as a potential risk factor.
\end{abstract}

Keywords: Working Hours, Obesity, Mediator Model, Chinese Adult Workers

\section{Introduction}

In recent decades, with the continuous development of social economy, the prevention and control of obesity and related chronic diseases are highly concerned in the world. Obesity is an important risk factor for inducing diseases such as cardiovascular disease, stroke, metabolic syndrome, type 2 diabetes, and multiple cancers. Meanwhile, the incidence of obesity is increasing rapidly worldwide, and has constituted one of the major public health challenges threatening human health.

As a complex and multifactorial disease, obesity is the result of the combination of genetic susceptibility, unhealthy behavior, psychosocial stress and environment [1]. Early studies on obesity, most scholars believe that genetic is the main factor affecting obesity $[2,3]$. But with the development of social economy, the factors affecting obesity are becoming more and more complicated. Besides genetics, people's eating habits, physical activity and health care, income level and other factors are also important factors affecting obesity $[4,5]$. Poor eating habits, excessive caloric intake and lack of exercise lead to weight gain, which significantly increase the risk of obesity [6-8]. About the relationship between income levels and obesity, there is a nonlinear relationship between income levels and obesity, which means it is related to the country's income level, and in high-income countries, the poor are more likely to be obese [9].

Job characteristics can also affect obesity, including working place, hours, environment, requirements [10]. Studies have shown that working long hours is a risk factor for obesity, but current research on the relationship between working hours and obesity is not entirely consistent. Some 
researchers have found that long working hours significantly increases body mass index (BMI) and the risk of obesity [11]. The papers were analyzed on the relationship between working hours and obesity between 1995 and 2012, and found that $70 \%$ of the findings suggest that long-time work and short-time exercise significantly increase obesity [12]. However, some scholars found that working hours had no significant effect on BMI [13]. Although previous literature examined the relationship between working hours and obesity, few studied whether exercise time and sleep time have a common mediating effect, and which effect is stronger. At the same time, there are still few studies on the relationship between working hours and obesity among Chinese urban workers.

Since China's reform and opening up in 1978, great changes have taken place in China's social structure and economic system. The process of industrialization and urbanization has been advancing, people's living standards have improved significantly, and dietary nutrition has become increasingly balanced. However, because of the short course of marketization, the transformation and upgrading of industrial structure, the increase of international business and domestic demand, the competition in the labor market has become more intense. At the same time, due to the imperfection of the relevant system, the contradictions in the labor market become increasingly prominent, problems such as "996 work system "and" sub-health "have emerged in endlessly, and overtime work has become the norm for urban workers in China. China's obesity rate has also grown in the past few decades in an "explosive "growth. Some researchers studied mortality, morbidity and risk factors in China and its provinces among 1990-2017 and found that obesity was one of the top 10 risk factors leading to the death and disease burden of the Chinese population [14]. Therefore, examining the relationship between working hours and obesity of urban workers in China, examining whether there are common mediating effects of exercise time and sleep time, has positive theoretical significance and practical value for deeply understanding the conduction mechanism of long-term work affecting obesity, and will also provide scientific basis for establishing more reasonable public health policy to prevent and control obesity.

\section{Data Sources, Model Design and Variable Selection}

\subsection{Data Sources}

The data used in this paper are from the 2018 China Family Panel Studies (CFPS for short). The database is a large-scale micro-family household survey conducted by the China Social Science Survey Center of Peking University. It can reflect the social, economic, population, education and health changes in china by tracking the data of individual, family and community levels. CFPS conducted its initial and follow-up surveys in Beijing, Shanghai and Guangdong in 2008 and 2009 and officially conducted visits in 2010. This study is based on the latest survey data of 2018, considering the working time validity of the rural samples, this paper only keeps the sample of urban workers aged 18-65 years old. And the final sample size included 1727, male sample 987, and female sample 740 .

\subsection{Model Design}

To examine the effects of working hours on obesity, the benchmark regression model is:

$$
\text { Obesity }_{\mathrm{i}}=\mathrm{a}_{0}+\mathrm{a}_{1} \mathrm{WT}_{\mathrm{i}}+\mathrm{a}_{2} \mathrm{CV}_{\mathrm{i}}+\mathrm{u}_{\mathrm{i}}
$$

Obesity $_{\mathrm{i}}$ is the obesity variable, $\mathrm{WT}_{\mathrm{i}}$ is the working time variable, $\mathrm{CV}_{\mathrm{i}}$ is control variable that affects obesity, $\mathrm{u}_{\mathrm{i}}$ is the random disturbance term. At the same time, in order to further investigate the direct effect of working time on obesity, and the indirect effect of working time on obesity by affecting exercise time and sleep time, this paper uses the mediator model to analyze. The mediator model is:

$$
\begin{gathered}
\mathrm{M}_{\mathrm{i}}=\mathrm{b}_{0}+\mathrm{b}_{1} \mathrm{WT}_{\mathrm{i}}+\mathrm{b}_{2} \mathrm{CV}_{\mathrm{i}}+\mathrm{u}_{\mathrm{i}} \\
\text { Obesity }_{\mathrm{i}}=\mathrm{c}_{0}+\mathrm{c}_{1} \mathrm{WT}_{\mathrm{i}}+\mathrm{c}_{2} \mathrm{M}_{\mathrm{i}}+\mathrm{c}_{3} \mathrm{CV}_{\mathrm{i}}+\mathrm{u}_{\mathrm{i}} \\
\text { Obesity }_{\mathrm{i}}=\left(\mathrm{c}_{0}+\mathrm{c}_{2} \mathrm{~b}_{0}\right)+\left(\mathrm{c}_{1}+\mathrm{c}_{2} \mathrm{~b}_{1}\right) \mathrm{WT}_{\mathrm{i}}+\left(\mathrm{c}_{3}+\mathrm{c}_{2} \mathrm{~b}_{2}\right) \mathrm{CV}_{\mathrm{i}}+\mathrm{u}_{\mathrm{i}}
\end{gathered}
$$

The formula (4) is the outcome by getting formula (2) into the formula (3). $a_{1}$ in formula (1) is the total effect of working hours on obesity. $b_{1}$ in formula (2) is the effect of working time on mediating variables, including exercise time and sleep time. $c_{1}$ in formula (3) is the direct effect of working hours on obesity. $c_{2} b_{1}$ in formula (4) is the indirect effect of working hours on obesity through mediating variables $\mathrm{M}_{\mathrm{i}}$.

\subsection{Variable Selection}

The explained variable of this paper is whether the urban workers are obese or not, and when the obesity standard is reached, the assignment is 1 , otherwise the assignment is 0 . Regarding the measures of obesity, the main international popularity are BMI, WHR, waist circumference and skin fold thickness, etc. According to CFPS (2018) data, obesity in this paper is mainly measured by BMI. And BMI is the ratio of body weight $(\mathrm{kg})$ to height $(\mathrm{m})$ squared which is the most commonly used tool to measure overweight and obesity internationally. There are three sets of BMI measures of obesity, which are WHO standard, Asian standard and Chinese standard, as shown in Table 1. Working Group on Obesity in China (WGOC) aimed at the characteristics of the Chinese people, proposed a threshold in 2003 defining the extent of overweight and obesity in China which was designated by the Ministry of Health in 2013 as the People's Republic of China Health Industry Standard (Adult Weight Standard). Therefore, this study mainly defines obesity according to Chinese standards. For the obesity variable, when 28.0BMI, the assignment is 1 , otherwise 0 .

The core explanatory variable of this paper is working time. For the working time variable, it is measured by the weekly working time. At the same time, the variable is divided into 
three categories: the weekly working time is less than 40 hours, equal to 40 hours, and greater than 40 hours. The Labor Law of the People's Republic of China stipulates that workers work eight hours a day and 40 hours a week.

In addition to working time variables, this paper introduces other control variables that affect obesity, including individual characteristic variables, life habits variables, and mediation variables. Individual characteristic variables include gender, age, education level, income level. Lifestyle variables include whether to smoke or drink. Mediation variables include weekly exercise time and working-day sleep time.

For gender variables, this paper assigns male to 1 and female to 0 . For age variables, in order to investigate whether the obesity status of workers has an inverted "U" type relationship with age, this paper introduces the age square variable. For the education level variable, this study divides this variable into three categories: high school and below, college and university (CU), master and above (MA). For the income level variable, this paper uses the employee's after-tax monthly salary to measure, simultaneously takes the logarithm processing.

For smoking variables, this paper assigns smoking to 1 and non-smoking to 0 . For drinking variables, this paper assigns drinking more than three times a week to 1 , or 0 . For weekly exercise variables, this paper assigns a weekly exercise duration of less than 3.5 hours (less than 30 minutes per day) to 1 , or 0 . For the working day sleep duration variable, this paper assigns the working day sleep duration less than 8 hours to 1 , otherwise 0 . The descriptive statistical analysis of the above variables is shown in Table 2.

Table 1. BMI measures of obesity.

\begin{tabular}{llll}
\hline BMI Classification & WHO Standard & Asian Standards & Chinese Standards \\
\hline Thin & $\mathrm{BMI}<18.5$ & $\mathrm{BMI}<18.5$ & $\mathrm{BMI}<18.5$ \\
Normal & $18.5 \leq \mathrm{BMI}<25.0$ & $18.5 \leq \mathrm{BMI}<23.0$ & $18.5 \leq \mathrm{BMI}<24.0$ \\
Overweight & $25.0 \leq \mathrm{BMI}<30.0$ & $23.0 \leq \mathrm{BMI}<25.0$ & $24.0 \leq \mathrm{BMI}<28.0$ \\
Obesity & $30.0 \leq \mathrm{BMI}$ & $25.0 \leq \mathrm{BMI}$ & $28.0 \leq \mathrm{BMI}$ \\
\hline
\end{tabular}

Table 2. Descriptive statistical analysis of variables.

\begin{tabular}{lllll}
\hline Variables & Mean & $\begin{array}{l}\text { Standard } \\
\text { Deviation }\end{array}$ & $\begin{array}{l}\text { Least } \\
\text { Value }\end{array}$ & $\begin{array}{l}\text { Crest } \\
\text { Value }\end{array}$ \\
\hline Obesity & 0.113 & 0.317 & 0 & 1 \\
Overweight & 0.235 & 0.474 & 0 & 1 \\
Weekly working hours & 49.027 & 11.806 & 30 & 84 \\
Sex & 0.572 & 0.495 & 0 & 1 \\
Age & 32.760 & 7.508 & 18 & 65 \\
Education level & 13.158 & 3.338 & 0 & 22 \\
Monthly after-tax income & 4470.197 & 3297.419 & 800 & 48000 \\
Smoking & 0.305 & 0.461 & 0 & 1 \\
Drinking & 0.133 & 0.339 & 0 & 1 \\
Week exercise time & 4.300 & 3.435 & 0.1 & 21 \\
Working day sleep time & 7.565 & 1.007 & 5 & 14 \\
\hline
\end{tabular}

\section{Empirical Results Analysis}

\subsection{Benchmark Regression Analysis}

In the benchmark regression analysis, this paper first examined the effect of working hours on obesity, and then in turn included individual characteristic variables and life habit variables. the relevant results are shown in table 3 . From the model (1) to the model (3), it can be seen that urban workers who work 40 hours a week and work more than 40 hours a week are more likely to suffer from obesity than those who work less than 40 hours a week. The results are consistent with one study that studied the relationship between weekly working hours and obesity among working adults in the United States, also found that working adults in the United States who worked 40 hours and over 40 hours a week were more likely to be obese than adults who worked less than 40 hours a week [1].

One possible explanation for the relationship between working hours and obesity is that working hours take up exercise time and sleep time for workers. Studies have shown that shorter exercise time and lack of sleep significantly increase obesity. Research analyzed 39 papers on the relationship between working hours and obesity between 1995 and 2012, and found that 70\% of the findings suggest that long-term work and short-time exercise significantly increase obesity [13]. And the findings of Jens (2015) suggest that sleep deprivation is also an important factor in increasing the probability of obesity [15]. Since China's reform and opening up in 1978, people's living standards have been rapidly improved. At the same time, because of the short process of marketization of the Chinese economy, the unreasonable industrial structure and the imperfect related system, the contradictions in the labor market are becoming more and more prominent, and the problems of "996 work system "and" sub-health "are emerging in endlessly. In addition to the improvement of living conditions and the excessive intake of high protein and high calorie food, the increasing number of overtime work and extra long working hours are also crowding out the exercise and health care time and sleep time of Chinese urban workers, thus increasing the probability of obesity, which cannot be ignored.

Table 3. Logit regression results of effects of working hours on obesity.

\begin{tabular}{llll}
\hline \multirow{2}{*}{ Variables } & $(\mathbf{1})$ & $(\mathbf{2})$ & $(\mathbf{3})$ \\
\cline { 2 - 4 } & obesity & obesity & obesity \\
\hline Hour $>40$ & $2.034^{* * *}$ & $2.100^{* * *}$ & $2.032^{* * *}$ \\
& $(0.590)$ & $(0.597)$ & $(0.597)$ \\
Hour $=40$ & $1.277^{* *}$ & $1.186^{*}$ & $1.148^{*}$ \\
& $(0.606)$ & $(0.611)$ & $(0.611)$ \\
Sex & & $0.595^{* * *}$ & $0.373^{*}$ \\
& & $(0.180)$ & $(0.203)$ \\
Age & & 0.102 & 0.0843 \\
& & $(0.0678)$ & $(0.0690)$ \\
Age2 & & -0.0907 & -0.0724 \\
& & $(0.0934)$ & $(0.0951)$ \\
CU & & $0.441^{* *}$ & $0.526^{* * *}$ \\
& & $(0.175)$ & $(0.180)$ \\
MA & & $1.768^{* * *}$ & $1.787^{* * *}$ \\
& & $(0.312)$ & $(0.316)$ \\
\hline
\end{tabular}




\begin{tabular}{llll}
\hline \multirow{2}{*}{ Variables } & $\mathbf{( 1 )}$ & $\mathbf{( 2 )}$ & $\mathbf{( 3 )}$ \\
\cline { 2 - 4 } & obesity & obesity & obesity \\
\hline Lnwage & & -0.0843 & -0.0544 \\
& & $(0.157)$ & $(0.158)$ \\
Smoking & & 0.144 \\
& & $(0.188)$ \\
Drinking & & & $0.798^{* * *}$ \\
& & & $(0.196)$ \\
Constant & $-3.807^{* * *}$ & $-6.172^{* * *}$ & $-6.098^{* * *}$ \\
& $(0.584)$ & $(1.754)$ & $(1.776)$ \\
Observations & 1,727 & 1,727 & 1,727 \\
\hline
\end{tabular}

Standard errors in parentheses $* * * \mathrm{p}<0.01,{ }^{* *} \mathrm{p}<0.05, * \mathrm{p}<0.1$.

For control variables, gender variables were significantly positive either model (2) or model (3), suggesting a greater probability of obesity among male urban workers in China compared to women which is consistent with the results of existing literature. Peng N. etal (2019) analyzed the trend of obesity in China between 1991 and 2011, and found that the increase of BMI in men significantly exceeded that in women [5]. This may be because men are the main force in the labor market, living under greater pressure and working longer hours, which leads to a greater probability of male obesity.

For age variables, the regression coefficient of one term is positive and the regression coefficient of square term is negative, which indicates that there is an inverted " $U$ " type relationship between obesity status and age of urban workers in Chinese cities and towns, but these two variables are not significant.

For the education level variables, college and university, master and above are more likely to suffer from obesity than high school and below whether model (2) or model (3) which is inconsistent with the results of existing literature. Bockerman P. et al (2017) found that education may be a protective factor against obesity [16]. One possible reason for the positive correlation between education and obesity among Chinese urban workers is that the higher the level of education, the more likely it is to work in big cities. Big cities not only live faster, work stress intensity may also be greater, resulting in a higher risk of obesity.

For income variables, model (2) and model (3) showed that income promotion reduced the probability of obesity, but the two variables were not significant. A nonlinear relationship was found between income and obesity which related to the country's income level, and in high-income countries, the poor are the most obese, but the overall obesity rate in all countries in the world is rising [9].

Model (3) further examined the effects of smoking and drinking (drinking more than 3 times a week) on obesity. Regression results showed that smoking had no significant effect on obesity, whereas drinking variables significantly increased obesity which is consistent with the results of existing literature. U.S. National Health Tracking Survey Data was used to examine the association of heavy drinking with obesity and found that heavy drinking significantly increased the probability of obesity [17].

\subsection{Mediator Model Analysis}

To analyze the conduction mechanism of working time affecting obesity, two mediating variables, the weekly exercise time variable and the working day sleep time variable, were included in this paper. At the same time, less than 3.5 hours of weekly exercise time (less than 30 minutes per day) is assigned to 1 , others to 0 , and working days sleep time less than 8 hours to 1 and others to 0 . It can be seen from table 4 that both mediating variables passed the significance test in the case of controlling other explanatory variables. It is inferred that weekly exercise time and working day sleep time are the mediating variables of working hours affecting obesity. Compared with the urban workers who work less than 40 hours a week, the weekly work equivalent of 40 hours has no significant effect on the weekly exercise time and sleep time of the urban workers, while working more than 40 hours a week significantly affects the weekly exercise time and sleep time of the urban workers, thus increasing their probability of obesity.

Specifically, model (4) in the table 4 confirms that working more than 40 hours a week significantly affects weekly exercise time (less than 30 minutes per day) at the 5\% level. After controlling the working time and weekly exercise time variables in model (5), the weekly exercise time variables significantly increased the probability of obesity among urban workers at the $1 \%$ level. This suggests that urban workers work more than 40 hours a week, which significantly reduces their weekly exercise time and indirectly increases their risk of obesity. Model (6) demonstrated that working more than 40 hours a week significantly affects working-day sleep time at a level of 5\% (sleep less than 8 hours per day). After controlling the work-time and sleep-time variables in model (7), the sleep-time variables at a level of $1 \%$ significantly increased the probability of obesity among urban workers. This suggests that urban workers work more than 40 hours a week, significantly reducing their working-day sleep time and indirectly increasing their risk of obesity. According to the model (8), in the conduction mechanism of working hours affecting obesity, both exercise and sleep time play an intermediary role, that is, working more than 40 hours a week cannot only directly increase the probability of obesity among urban workers, but also indirectly increase the probability of obesity by reducing their weekly exercise time and sleep time. However, compared with urban workers who work less than 40 hours a week, the mediator effect of 40 hours a week is not significant. Furthermore, the mediating effect of the weekly exercise time variable can be calculated as $0.2616(=0.378 * 0.692)$ by model (4) and model (8). The mediating effect of the sleep time variable can be calculated as $0.2305(=0.388 * 0.594)$ by model (6) and (8). This indicates that the mediating effect of weekly exercise time is greater than that of sleep time in the mechanism of working time affecting obesity. Therefore, compared with urban workers who work less than 40 hours a week, working more than 40 hours a week is more likely to increase the probability of obesity by affecting the exercise time of workers, and then affecting their BMI. 
Table 4. Mediating mechanisms of working hours affecting obesity.

\begin{tabular}{|c|c|c|c|c|c|}
\hline \multirow{2}{*}{ Variables } & (4) & (5) & (6) & (7) & (8) \\
\hline & exercise & obesity & sleep & obesity & obesity \\
\hline \multirow[t]{2}{*}{ Hour $>40$} & $0.378 * *$ & $1.965 * * *$ & $0.388 * *$ & $1.967 * * *$ & $1.893 * * *$ \\
\hline & $(0.187)$ & $(0.598)$ & $(0.191)$ & $(0.597)$ & $(0.598)$ \\
\hline \multirow[t]{2}{*}{ Hour $=40$} & 0.113 & $1.119^{*}$ & -0.0798 & $1.165^{*}$ & $1.129 *$ \\
\hline & $(0.194)$ & $(0.613)$ & $(0.199)$ & $(0.612)$ & $(0.613)$ \\
\hline \multirow[t]{2}{*}{ Exercise } & & $0.748 * * *$ & & & $0.692 * * *$ \\
\hline & & $(0.171)$ & & & $(0.172)$ \\
\hline \multirow[t]{2}{*}{ Sleep } & & & & $0.657 * * *$ & $0.594 * * *$ \\
\hline & & & & $(0.163)$ & $(0.165)$ \\
\hline \multirow[t]{2}{*}{ Sex } & 0.0136 & $0.364 *$ & 0.187 & 0.338 & 0.334 \\
\hline & $(0.121)$ & $(0.204)$ & $(0.121)$ & $(0.205)$ & $(0.206)$ \\
\hline \multirow[t]{2}{*}{ Age } & 0.0282 & 0.0814 & $0.0926^{* *}$ & 0.0614 & 0.0594 \\
\hline & $(0.0435)$ & $(0.0691)$ & $(0.0430)$ & $(0.0693)$ & $(0.0695)$ \\
\hline \multirow[t]{2}{*}{ Age2 } & -0.0651 & -0.0652 & $-0.107 *$ & -0.0443 & -0.0382 \\
\hline & $(0.0621)$ & $(0.0955)$ & $(0.0610)$ & (0.0957) & $(0.0961)$ \\
\hline \multirow[t]{2}{*}{$\mathrm{CU}$} & 0.118 & $0.498 * * *$ & 0.176 & $0.481 * * *$ & $0.456 * *$ \\
\hline & $(0.111)$ & $(0.181)$ & $(0.111)$ & $(0.181)$ & $(0.182)$ \\
\hline \multirow[t]{2}{*}{ MA } & $0.739 * * *$ & $1.673 * * *$ & $0.511 * *$ & $1.716^{* * *}$ & $1.616^{* * *}$ \\
\hline & $(0.277)$ & $(0.320)$ & $(0.258)$ & $(0.319)$ & $(0.323)$ \\
\hline \multirow[t]{2}{*}{ Lnwage } & $0.184^{*}$ & -0.0696 & 0.0926 & -0.0581 & -0.0754 \\
\hline & $(0.102)$ & $(0.160)$ & $(0.101)$ & $(0.161)$ & $(0.162)$ \\
\hline \multirow[t]{2}{*}{ Smoking } & -0.200 & 0.182 & -0.0342 & 0.155 & 0.192 \\
\hline & $(0.124)$ & $(0.189)$ & $(0.124)$ & $(0.189)$ & $(0.191)$ \\
\hline \multirow[t]{2}{*}{ Drinking } & -0.200 & $0.843 * * *$ & 0.213 & $0.773 * * *$ & $0.817 * * *$ \\
\hline & $(0.151)$ & (0.199) & $(0.151)$ & (0.197) & $(0.200)$ \\
\hline \multirow[t]{2}{*}{ Constant } & $-1.815^{*}$ & $-6.356 * * *$ & $-3.266 * * *$ & $-5.883 * * *$ & $-6.071 * * *$ \\
\hline & (1.052) & $(1.793)$ & $(1.053)$ & (1.783) & (1.799) \\
\hline Observations & 1,727 & 1,727 & 1,727 & 1,727 & 1,727 \\
\hline
\end{tabular}

\section{Heterogeneity Analysis of Working Hours Affecting Obesity}

Considering the possible differences between different genders and different income classes, this paper conducts a gender sample and income class sample analysis to examine the heterogeneous effects of work time on obesity. For the income class, this paper takes the after-tax wage sample mean as the dividing line, the after-tax wage above the sample mean is defined as the high income group, and the after-tax wage below the sample mean is defined as the low income group. The specific regression results are shown in table 5 .

Table 5. Heterogeneous regression results.

\begin{tabular}{lllll}
\hline Variables & $\mathbf{( 9 )}$ & $\mathbf{( 1 0 )}$ & $\mathbf{( 1 1 )}$ & $\mathbf{( 1 2 )}$ \\
\cline { 2 - 5 } Hour $>40$ & $1.688^{* *}$ & $2.424^{* *}$ & $1.889^{*}$ & $2.055^{* * *}$ \\
& $(0.737)$ & $(1.027)$ & $(1.033)$ & $(0.735)$ \\
Hour=40 & 0.925 & 1.295 & 1.059 & 1.119 \\
& $(0.756)$ & $(1.053)$ & $(1.051)$ & $(0.756)$ \\
Sex & & & 0.393 & $0.431^{*}$ \\
& & & $(0.364)$ & $(0.257)$ \\
Age & 0.0411 & 0.218 & -0.0460 & $0.156^{*}$ \\
& $(0.0782)$ & $(0.164)$ & $(0.116)$ & $(0.0920)$ \\
Age2 & -0.0186 & -0.242 & 0.0965 & -0.163 \\
& $(0.107)$ & $(0.233)$ & $(0.161)$ & $(0.127)$ \\
CU & $0.564 * * *$ & 0.436 & $0.620^{* *}$ & 0.378 \\
& $(0.215)$ & $(0.331)$ & $(0.299)$ & $(0.230)$ \\
MA & $1.229 * *$ & $2.153^{* * *}$ & $1.082^{* *}$ & $2.605^{* * *}$ \\
& $(0.495)$ & $(0.445)$ & $(0.521)$ & $(0.438)$ \\
Lnwage & -0.0230 & 0.0204 & 0.153 & 0.416 \\
\hline
\end{tabular}

\begin{tabular}{lllll}
\hline \multirow{2}{*}{ Variables } & $\mathbf{( 9 )}$ & $\mathbf{( 1 0 )}$ & $\mathbf{( 1 1 )}$ & $\mathbf{( 1 2 )}$ \\
\cline { 2 - 5 } & Male & Female & High Group & Low Group \\
\hline \multirow{2}{*}{ Smoking } & $(0.191)$ & $(0.295)$ & $(0.334)$ & $(0.351)$ \\
\multirow{2}{*}{ Drinking } & 0.215 & -0.715 & 0.441 & -0.128 \\
& $(0.198)$ & $(0.800)$ & $(0.280)$ & $(0.258)$ \\
\multirow{2}{*}{ Constant } & $0.744^{* * *}$ & $1.123^{* *}$ & $0.525^{*}$ & $0.948^{* * *}$ \\
& $(0.214)$ & $(0.513)$ & $(0.314)$ & $(0.257)$ \\
Observations & $-4.870^{* *}$ & $-9.527^{* *}$ & -5.557 & $-11.10^{* * *}$ \\
& $(2.101)$ & $(3.758)$ & $(3.395)$ & $(3.261)$ \\
\hline
\end{tabular}

From the models (9) and (10), it can be seen that for both male and female samples, working more than 40 hours a week significantly increases the risk of obesity among male and female urban workers at the $5 \%$ level compared with those working less than 40 hours a week, and the impact on women is greater. According to the previous analysis of the mediating effects, working more than 40 hours a week has a greater mediating effect on obesity through exercise time. For female urban workers, if there is a phenomenon of overtime, they will exercise less than men, because women also have to take more family labor time. The concept of sharing family services between men and women has gained greater acceptance with the development of society, but women still bear more domestic work than men on average. Therefore, if female urban workers work more than 40 hours a week, they will not only affect their sleep time, but they will also reduce more exercise time. Thus they are more likely to suffer from obesity than male workers.

According to the model (11), for the high-income group samples, working more than 40 hours a week significantly increased the risk of obesity among workers in the high-income group at the level of $10 \%$ compared with the urban workers who worked less than 40 hours a week, and 40 hours a week did not pass the significance test. According to the model (12), for the low-income group samples, working more than 40 hours a week significantly increased the risk of obesity among workers in the low-income group at the $1 \%$ level compared with the urban workers who worked less than 40 hours a week, and 40 hours a week did not pass the significance test. In addition, compared with urban workers who work less than 40 hours a week, working more than 40 hours a week has a greater impact on the low-income group than on the high-income group, indicating that low-income urban workers are more likely to suffer from obesity than high-income groups if working more than 40 hours a week. One possible reason is that, compared with workers in low-income groups, workers in high-income groups pay more attention to their own health status, have more ability to maintain balanced dietary nutrition, and have more conditions to increase the opportunities and frequency of exercise health care, thus maintaining a better body shape.

\section{Conclusions}

This paper makes an empirical analysis of how working hours affect the obesity of urban workers in China, and finds that overtime work can significantly increase the probability of obesity of urban workers. Mediator model analysis found 
that sleep time and weekly exercise time were two significant mediating variables that overtime work affected obesity in urban workers. The results of sample regression showed that overtime work had a greater impact on obesity in women and low-income urban workers than in men and high-income groups. As a complex multifactorial disease, obesity should not only consider genetic, dietary and environmental factors, but also the weekly working hours of workers should be considered as a potential risk factor. In order to improve the public health of urban workers and reduce the probability of obesity for urban workers during long working hours, the state government departments should further implement the relevant provisions on the legal working hours of workers, limit illegal and long-term work, strive to promote the regularization of working hours in the labor market, ensure the right of workers to rest, and improve the public health of urban workers.

\section{Acknowledgements}

This paper is funded by the National Social Science Foundation of China Youth Project "The impact of digital economic development on the total amount of employment, structure and quality and the study of promotion mechanism (20CJY015)", China Postdoctoral Science Foundation's 68 approved projects "Research on Dynamic Monitoring and Cooperative Governance of Quantity and Quality" and "Study on the Impact of Digital Economy Development on the Quality of Employment and the Promotion Mechanism". We want to express our heartfelt thanks to National Social Science Foundation of China and Beijing Normal University.

\section{References}

[1] Doerrmann, C., Oancea, S. C. and Selya, A. (2020). The association between hours spent at work and obesity status: results from NHANES 2015 to 2016. American Journal of Health Promotion, 34 (4): 359-365.

[2] Anthony, G. C. and David, B. A. (1998). The search for human obesity genes. Science Magazine, 280 (5368): 1374-1377.

[3] David, C. (2002). Population strategies to prevent obesity: only few studies attempted so far and with limited success (Editoroals). British Medical Journal, 325 (7367): 728-729.

[4] Tomas, J. P. and A. P. Richard. (2003). The long-run growth in obesity as a function of technological change. Perspectives in Biology and Medicine, 46 (3): 87-107.

[5] Peng, N., Lanlin, D. and S. P. Alfonso. (2019). Decomposing adult obesity trends in China (1991-2011). Economics and Human Biology, 34 (8): 5-15.

[6] Brown, T., Avenell, A., Edmunds, L. D., Moore, H., Whittaker, V. and L. Avery. (2009). Systematic review of long-term lifestyle interventions to prevent weight gain and morbidity in adults. Obesity Reviews, 10 (6): 627-638.

[7] Hebden, L., Chey, T. and M. Alman-Farinelli. (2012). Lifestyle intervention for preventing weight gain in young adults: a systematic review and meta-analysis of RCTs. Obesity Reviews, 13 (8): 692-710.

[8] Amin, V., Dunn, P. and T. Spector. (2018). Does education attenuate the genetic risk of obesity? Evidence from U.K. Twins. Economics and Human Biology, 31 (9): 200-208.

[9] Ameye, H. and J. Swinnen. (2019). Obesity, income and gender: The changing global relationship. Global Food Security, 23 (9): 267-281.

[10] Caruso, C. C., Bushell, T., Eggerth, D., Heitmann, A., Kojola, B., Newman, K., Rosa, R. and S. L. Sauter. (2006). Long working hours, safety, and health: toward a national research agenda. American Journal of Industrial Medicine, 49 (11): 930-942.

[11] Van, H. M. (2003). Long workhours and health. Scandinavian Journal of Work Environment and Health, 29 (3): 171-188.

[12] Magee, C. A., Caputi, P. and D. C. Iverson. (2010). Short sleep mediates the association between long work hours and increased body mass index. Journal of Behavioral Medicine, 34 (2): 83-91.

[13] Marianna, V., Jane, E. F., Archana, S. M., Martin, J. S., Jussi, V., Michael, G. M. and K. Mika. (2010). Overtime work and incident coronary heart disease: the Whitehall II prospective cohort study. European Heart Journal, 31 (14): 1737-1744.

[14] Zhou, M. Haidong W., Xinying, Z., Peng, Y., Jun, Z. and Wanqing, C. (2019). Mortality, morbidity, and risk factors in China and its provinces, 1990-2017: a systematic analysis for the global burden of disease study 2017. Lancet, 394 (10204): 1145-1158.

[15] Jens, B. (2015). Trends in short and long sleep in Denmark from 1964 to 2009, and the associations with employment, SES (socioeconomic status) and BMI. Sleep Medicine, 16 (3): 385-390.

[16] Böckerman, P., Viinikainen, J., Laura, P. R., and C. Hakulinen. (2017). Does higher education protect against obesity? Evidence using mendelian randomization. Preventive Medicine, 101 (8): 195-198.

[17] Tera, L. F. Kimberly, F., Kenneth, J. S., Debra, K. S. and B. Christie. (2017). Heavy drinking in young adulthood increases risk of transitioning to obesity. American Journal of Preventive Medicine, 53 (2): 169-175. 